\title{
Alternatif Menentukan Persamaan Garis Simggung Hiperbola
}

\author{
Sri Rahayuningsih \\ MAN 1 Pekanbaru
}

\begin{tabular}{l}
\hline \multicolumn{1}{c}{ INFO ARTIKEL } \\
\hline Riwayat Artikel: \\
Diterima: 03-10-2020 \\
Disetujui: \\
Diterbitkan:
\end{tabular}

\section{Kata kunci:}

Garis Singgung

Garis Tengah Sekawan

Hiperbola

Sifat Optis

\author{
Alamat Korespondensi: \\ Sri Rahayuningsih \\ MAN 1 Pekanbaru \\ E-mail: srirahayu11673@gmail.com
}

\begin{abstract}
Hyperbola interface equations are usually obtained by replacing the equation of lines in the hyperbola to obtain quadratic equations. Since the line offends hyperbola at a point, the discriminant value of the quadratic equation is zero, so a constant value is obtained. Then replace the equation with the line to get the tangent equation for the hyperbola. This article discusses the alternative of determining the tangent equation of the hyperbola using optical properties to determine the tangent equation through a given point and a friend's centerline to determine the tangent equation of a given gradient.
\end{abstract}

ABSTRAK

\begin{abstract}
Abstrak: Persamaan garis singgung hiperbola biasanya diperolah dengan cara mensubstitusikan persamaan garis pada hiperbola sehingga diperoleh persamaan kuadrat. Karena garis menyinggung hiperbola di satu titik, maka nilai diskriminan persamaan kuadrat tersebut sama dengan nol, sehingga diperoleh nilai konstanta. Kemudian substitusikan pada persamaan garis untuk memperoleh persamaan garis singgung hiperbola. Pada tulisan ini dibahas alternatif menentukan persamaan garis singgung hiperbola menggunakan sifat optis untuk menentukan persamaan garis singgung yang melalui titik tertentu dan garis tengah sekawan untuk menentukan persamaangaris singgung yang mempunyai gradien tertentu.
\end{abstract}

\section{LATAR BELAKANG}

Semua siswa harus memiliki kesempatan dan dukungan yang diperlukan untuk belajar matematika secara mendalam dan dengan pemahaman. Tidak ada pertentangan antara kesetaraan dan keunggulan (De walle, 2007). Geometri sebagai salah satu dari cabang matematika, yang dapat didefinisikan sebagai salah satu cabang matematika yang mempelajari tentang bentuk, ruang, komposisi beserta sifat-sifatnya, ukurannya dan hubungannya antara yang satu dengan yang lain. Irisan kerucut adalah lokus dari semua titik yang membentuk kurva dua dimensi, yang terbentuk dari irisan sebuah kerucut dengan sebuah bidang. Salah satu bentuk irisan kerucut adalah hiperbola (Mashadi, 2012; Susanto, 2012: Verber, 2011).

Garis singgung kurva adalah garis lurus yang hanya menyentuh kurva pada titik tertentu dan memiliki lereng yang sama sebagai fungsi pada titik itu. Pada umumnya di beberapa buku SMA/MA (Subardjo, 2004; Susanto, 2012), untuk menentukan persamaan garis singgung hiperbola dengan menggunakan gradien, substitusi dan diskriminasi. Penulis tertarik untuk merumuskan alternatif lain dalam mentukan persamaan garis singgung hiperbola dengan menggunakan pengetahuan dasar sederhana yang telah dimiliki siswa. Oleh karena itu Penulis merumuskan judul untuk tulisan ini "Alternatif Menentukan Persamaan Garis Singgung Hiperbola".

\section{GARIS SINGGUNG HIPERBOLA}

Hiperbola menurut geometri analitik didefinisikan sebagai tempat kedudukan titik-titik yang selisih jaraknya terhadap dua titik tertentu tetap harganya (Kanginan, 2000; Mashadi, 2012; Subardjo, 2004; Susanto, 2012; Weisberg, 2013). Dua titik tertentu itu disebut fokus hiperbola. Persaman 
hiperbola yang berpusat $O(0,0)$, dengan titik-titik fokus $F(-c, 0)$ dan $G(c, 0)$, yangtampak pada Gambar 1 adalah

$\frac{x^{2}}{a^{2}}-\frac{y^{2}}{b^{2}}=1$.

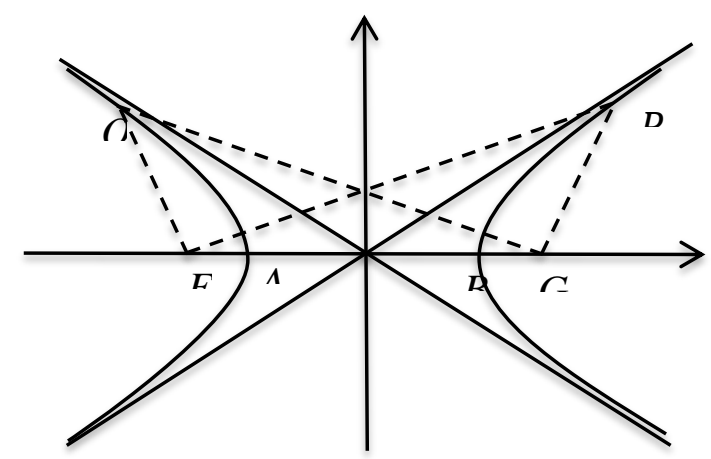

Gambar 1. Hiperbola Berpusat $\boldsymbol{O}(\mathbf{0}, \mathbf{0})$

Untuk menentukan persamaan hiperbola yang berpusat $(\alpha, \beta)$, dengan menggunakan transformasi yaitu menggeser $x$ sejauh $\alpha$ dan $y$ sejauh $\beta$ didapat persamaan

$\frac{(x-\alpha)^{2}}{a^{2}}-\frac{(y-\beta)^{2}}{b^{2}}=1$.

\section{Persamaan Garis Singgung Hiperbola di Titik $\left(\mathbf{x}_{1}, \mathbf{y}_{\mathbf{1}}\right)$}

Melalui sebuah titik yang terletak pada hiperbola, hanya dapat dibuat sebuah garis singgung. Menurut Subardjo (2004) persamaan garis singgung hiperbola di titik $\left(x_{1}, y_{1}\right)$ diperoleh dengan memisalkan terdapat dua buah titik pada Gambar 2, yaitu titik $P\left(x_{1}, y_{1}\right)$ dan titik $Q\left(x_{2}, y_{2}\right)$ yang terletak pada hiperbola. Gradien garis $P Q$ adalah

$$
m_{P Q}=\frac{y_{2}-y_{1}}{x_{2}-x_{1}} .
$$

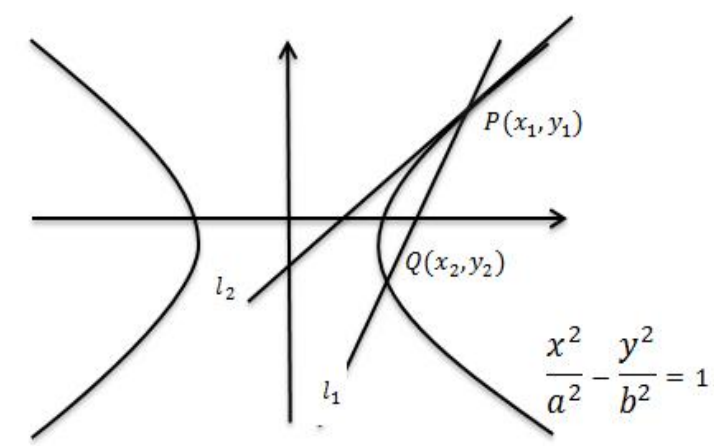

Gambar 2. Gambar Garis Singgung Hiperbola di Titik $\left(x_{1}, y_{1}\right)$

Hiperbola (1) melalui titik $P\left(x_{1}, y_{1}\right)$ dan $Q\left(x_{2}, y_{2}\right)$ maka

$$
\begin{aligned}
& b^{2} x_{1}{ }^{2}-a^{2} y_{1}{ }^{2}=a^{2} b^{2}, \\
& b^{2} x_{2}{ }^{2}-a^{2} y_{2}{ }^{2}=a^{2} b^{2} .
\end{aligned}
$$

Substitusikan persamaan (3) ke persamaan (4)

$$
\begin{aligned}
b^{2} x_{1}{ }^{2}-a^{2} y_{1}{ }^{2} & =b^{2} x_{2}{ }^{2}-a^{2} y_{2}{ }^{2} \\
a^{2}\left(y_{2}{ }^{2}-y_{1}{ }^{2}\right) & =b^{2}\left(x_{2}{ }^{2}-x_{1}{ }^{2}\right) \\
a^{2}\left(y_{2}-y_{1}\right)\left(y_{2}+y_{1}\right) & =b^{2}\left(x_{2}-x_{1}\right)\left(x_{2}+x_{1}\right)
\end{aligned}
$$

$\frac{\left(y_{2}-y_{1}\right)}{\left(x_{2}-x_{1}\right)}=\frac{b^{2}\left(x_{2}+x_{1}\right)}{a^{2}\left(y_{2}+y_{1}\right)}=m_{P Q}$

Dengan mensubstitusikan persamaan (5) pada persamaan garis $l_{1}$

$y-y_{1}=m\left(x-x_{1}\right)$ 
maka persamaan garis $l_{1}$ menjadi

$$
y-y_{1}=\frac{b^{2}\left(x_{2}+x_{1}\right)}{a^{2}\left(y_{2}+y_{1}\right)}\left(x-x_{1}\right) .
$$

Jika titik $Q$ digeser menjadi sangat dekat ke titik $P$ maka $x_{2}$ sangat dekat ke $x_{1}$ dan $y_{2}$ sangat dekat ke $y_{1}$ dan garis $l_{1}$ menjadi garis singgung hiperbola. Kemiringan dari garis $l_{2}$ di titik $\mathrm{P}\left(x_{1}, y_{1}\right)$ adalah $m=\lim m_{P Q}$, sehingga

$$
m=\lim m_{P Q}=\frac{b^{2} x_{1}}{a^{2} y_{1}} .
$$

Jadi, persamaan garis $l_{2}$ yang merupakan garis singgung adalah

$$
\begin{gathered}
y-y_{1}=\frac{b^{2} x_{1}}{a^{2} y_{1}}\left(x-x_{1}\right) \\
a^{2} y_{1} y-a^{2} y_{1}{ }^{2}=b^{2} x_{1} x-b^{2} x_{1}{ }^{2} \\
b^{2} x_{1} x-a^{2} y_{1} y=b^{2} x_{1}{ }^{2}-a^{2} y_{1}{ }^{2},
\end{gathered}
$$

dari persamaan (1) maka $b^{2} x_{1}{ }^{2}-a^{2} y_{1}{ }^{2}=a^{2} b^{2}$ sehingga $b^{2} x_{1} x-a^{2} y_{1} y=a^{2} b^{2}$.

Kedua sisi dibagi $a^{2} b^{2}$, diperoleh

$\frac{x_{1} x}{a^{2}}-\frac{y_{1} y}{b^{2}}=1$.

Persamaan (7) merupakan persamaan garis singgung di titik $\left(x_{1}, y_{1}\right)$ padahiperbola yang berpusat $O(0,0)$. Untuk persamaan garis singgung di titik $\left(x_{1}, y_{1}\right)$ pada hiperbola yang berpusat di $(\alpha, \beta)$ diperoleh dengan menggeser persamaan (7) sejauh $(\alpha, \beta)$ menjadi

$\frac{\left(x_{1}-\alpha\right)(x-\alpha)}{a^{2}}-\frac{\left(y_{1}-\beta\right)(y-\beta)}{b^{2}}=1$.

\section{PEMBAHASAN \\ Alternatif Persamaan Garis Singgung Hiperbola Sifat Optis Hiperbola}

Verberg et al (2011) menjelaskan sifat optis hiperbola, yaitu jika sebuah cahaya memancar dari satu fokus mengenai cermin akan dipantulkan kembali menjauhi fokus yang lain. Pada Gambar 3 garis $Q R$ merupakan garis singgung hiperbola dan berdasarkan Hukum Snellius maka $\alpha=\beta$. Karena sudut $S P R$ dan sudut $Q P F_{2}$ merupakan sudut yang bertolak belakang, maka $\angle S P R=\angle Q P F_{2}=\alpha$. Karena $\angle F_{1} P Q=\angle S P R=\angle Q P F_{2}$ maka garis singgung yang melalui suatu titik pada hiperbola membagi dua sama besar sudut-sudut antara garis-garis yang menghubungkan titik singgung dengan titik fokus (Sicelof, 1922: Varbert el all, 2011).

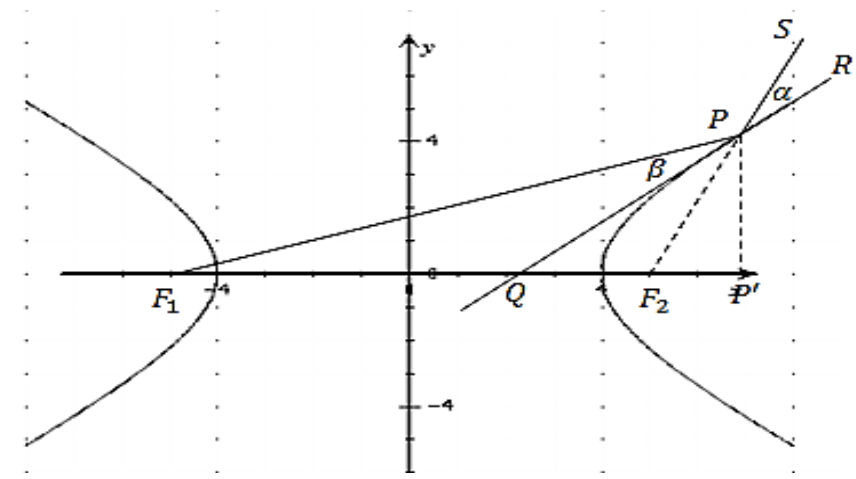

Gambar 3: Gambar Sifat Optis Hiperbola

\section{Garis Tengah Sekawan pada Hiperbola}

Garis tengah sekawan pada hiperbola adalah kedudukan titik-titik tengah tali busur yang sejajar (Sicelof, 1992; Susanto, 2012). Misalkan terdapat tali-tali busur hiperbola yang saling sejajarpada Gambar 4, dengan persamaan $y=m x+k$. 


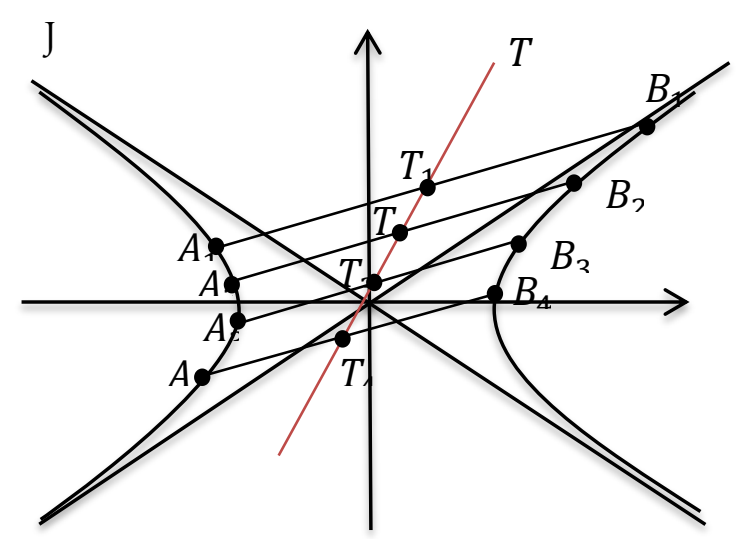

Gambar 4: Gambar Garis Tengah Sekawan Hiperbola

Dari Gambar 4 diketahui bahwa: 1) Titik $T_{1}, T_{2}, T_{3}$ dan $T_{4}$ adalah titik tengah tali busur $A_{1} B_{1}$, $A_{2} B_{2}, A_{3} B_{3}$ dan $\left.A_{4} B_{4} ; 2\right)$ Tali busur $A_{1} B_{1}, A_{2} B_{2}, A_{3} B_{3}$ dan $A_{4} B_{4}$ saling sejajar maka garis $T$ yang melalui $T_{1}, T_{2}, T_{3}$ dan $T_{4}$ merupakan garis tengah sekawan; dan 3) Garis tengah sekawan pada hiperbola tidak sejajar sumbu- $x$ maupun sumbu- $y$. Tali-tali busur tersebut melalui hiperbola maka

$$
\begin{gathered}
\frac{\left(\frac{y-k}{m}\right)^{2}}{a^{2}}-\frac{y^{2}}{b^{2}}=1 \\
b^{2}\left(\frac{y-k}{m}\right)^{2}-a^{2} y^{2}=a^{2} b^{2} \\
\left(b^{2}-a^{2} m^{2}\right) y^{2}-2 b^{2} k y-b^{2} k^{2}-a^{2} b^{2} m^{2}=0 .
\end{gathered}
$$

Karena $\mathrm{M}$ titik tengah tali busur, maka$$
y_{t}=\frac{1}{2}\left(y_{1}+y_{2}\right)=\frac{b^{2} k}{b^{2}-a^{2} m^{2}} .
$$$$
\text { Karena } k=y-m x \text {, maka }
$$$$
y_{t}=\frac{b^{2}(y-m x)}{b^{2}-a^{2} m^{2}}
$$

$y_{t}=\frac{b^{2}}{a^{2} m} x$

Jadi, persamaan (9) merupakan persamaan garis tengah sekawan pada hiperbola yang berpusat $O(0,0)$

\section{Persamaan Garis Singgung Hiperbola Menggunakan Sifat Optis}

Pada Gambar 3 misalkan titik $P\left(x_{1}, y_{1}\right)$ merupakan titik singgung pada hiperbola. Maka jarak $P$ terhadap $F_{1}$ adalah

Jarak $P$ terhadap $F_{2}$ adalah

$$
P F_{1}=\sqrt{\left(x_{1}-c\right)^{2}+y_{1}}
$$

Berarti $\left(P F_{2}\right)^{2}-\left(P F_{1}\right)^{2}=4 c x_{1}$, sedangkan

$$
P F_{2}=\sqrt{\left(x_{2}+c\right)^{2}+y_{1}} \text {. }
$$

$P F_{2}-P F_{1}=2 a$.

Jadi,

$$
P F_{2}+P F_{1}=\frac{2 c x_{1}}{a} \text {. }
$$

Dari persamaan (10) dan (11) diperoleh $P F_{1}=\frac{c}{a}\left(x_{1}-\frac{a^{2}}{c}\right)$ dan $P F_{2}=\frac{c}{a}\left(x_{1}+\frac{a^{2}}{c}\right)$.

Berdasarkan sifat optis dari hiperbola, terlihat bahwa garis $P Q$ dengan titik $Q\left(x_{t}, y_{t}\right)$ merupakan garis yang membagi sudut $F_{2} P F_{1}$, sehingga berlaku

$$
P Q=P F_{1} . P F_{2}\left(1-\frac{\left(F_{1} F_{2}\right)^{2}}{\left(P F_{1}+P F_{2}\right)^{2}}\right)
$$


94 Instructional Development Journal (IDJ), Vol. 3, No. 2, Agustus 2020, Hal. 90-95

$$
\begin{gathered}
P Q=\frac{c}{a}\left(x_{1}-\frac{a^{2}}{c}\right) \cdot \frac{c}{a}\left(x_{1}+\frac{a^{2}}{c}\right)\left(1-\frac{(2 c)^{2}}{\left(\frac{c}{a}\left(x_{1}-\frac{a^{2}}{c}\right)+\frac{c}{a}\left(x_{1}+\frac{a^{2}}{c}\right)\right)^{2}}\right) \\
P Q=\frac{c^{2}}{a^{2}}\left(\frac{c^{2} x_{1}{ }^{2}}{c^{2}}\right)\left(\frac{4 c^{2} x_{1}{ }^{2}-4 a^{2} c^{2}}{4 c^{2} x_{1}{ }^{2}}\right) \\
P Q=\frac{c^{2} x_{1}{ }^{2}}{a^{2}}-c^{2},
\end{gathered}
$$

karena $\frac{x_{1}^{2}}{a^{2}}-1=\frac{y_{1}^{2}}{b^{2}}$, maka

$$
P Q=\frac{c^{2} y_{1}^{2}}{b^{2}}
$$

Dari panjang $P Q=\frac{c^{2} y_{1}^{2}}{b^{2}}$ maka kemiringan garis $P Q$ adalah

$$
\begin{gathered}
m_{P Q}=\frac{P P^{\prime}}{\sqrt{(P Q)^{2}-\left(P P^{\prime}\right)^{2}}} \\
m_{P Q}=\frac{y_{1}}{\sqrt{\left(\frac{c^{2} y_{1}{ }^{2}}{b^{2}}\right)^{2}-y_{1}{ }^{2}}} \\
m_{P Q}=\frac{b^{2}}{\sqrt{c^{4} y_{1}^{2}-b^{4}}} .
\end{gathered}
$$

Dengan mensubstitusikan titik $P\left(x_{1}, y_{1}\right)$ dan gradien $m_{P Q}$ pada persamaan (6) diperoleh

$y=y_{1}+\frac{\left(x-x_{1}\right) b^{2}}{\sqrt{y_{1}^{2} c^{4}-b^{4}}}$

Jadi, persamaan (12) merupakan persamaan garis singgung hiperbola di titik $P\left(x_{1}, y_{1}\right)$ menggunakan sifat optis.

Persamaan Garis Singgung Hiperbola dengan Gradien m Menggunakan Garis Tengah Sekawan

Misalkan garis tengah sekawan (9) memotong hiperbola (1). dengan mensubstitusikan persamaan (9) ke persamaan (1) sehingga diperoleh

$x=\frac{ \pm m a^{2}}{\sqrt{m^{2} a^{2}-b^{2}}}$.

$$
\frac{x^{2}}{a^{2}}-\frac{\left(\frac{b^{2}}{a^{2} m} x\right)^{2}}{b^{2}}=1
$$

Substitusikan persamaan (13) pada persamaan (9) sehingga

$$
\begin{gathered}
y=\frac{b^{2}}{m a^{2}}\left(\frac{ \pm m a^{2}}{\sqrt{m^{2} a^{2}-b^{2}}}\right) \\
y=\frac{ \pm b^{2}}{\sqrt{m^{2} a^{2}-b^{2}}} .
\end{gathered}
$$

Jadi, koordinat titik potong garis tengah sekawan dan hiperbola adalah $\left(\frac{ \pm m a^{2}}{\sqrt{m^{2} a^{2}-b^{2}}}, \frac{ \pm b^{2}}{\sqrt{m^{2} a^{2}-b^{2}}}\right)$.Jika melalui titik tersebut ditarik garis yang menyinggung hiperbola, maka titik tersebut merupakan titik singgung, dengan mensubstitusikan titik singgung pada persamaan (6) diperoleh persamaan garis singgung berikut :

$$
y \pm \frac{b^{2}}{\sqrt{m^{2} a^{2}-b^{2}}}=m\left(x \pm \frac{m a^{2}}{\sqrt{m^{2} a^{2}-b^{2}}}\right)
$$




$$
y=m x \pm \sqrt{m^{2} a^{2}-b^{2}}
$$

Jadi, persamaan garis singgung dengan gradien $m$ dapat ditentukan dengan menggunakan garis tengah sekawan hiperbola.

\section{SIMPULAN}

Dari hasil tulisan ini dapat disimpulkan bahwa untuk menentukan garis singgung hiperbola di titik $\left(x_{1}, y_{1}\right)$ dapat diturunkan dengan menggunakan sifat optis hiperbola. Garis tengah sekawan hiperbola dapat digunakan untuk menurunkan persamaan garis singgung hiperbola dengan gradien $m$.

\section{DAFTAR RUJUKAN}

Kanginan, M \& Kustendi, T. (2000). Matematika 3A untuk SMU Kelas III. Jakarta: Grafindo.

Mashadi. (2012). Geometry. Pekanbaru: Pusbangdik Universitas Riau

Siceloff, L. P., G. Wentworth \& D. E. Smith. (1922). Analitic Geometry. Boston: Ginn and Company.

Subardjo. Y. (2004). Matematika 3A untuk SMU Kelas 3 Kurikulum 1994 Semester. Jakarta: Bumi Aksara.

Susanto. (2012). Geometri Analitik Datar. Bahan Ajar, Jurusan Pendidikan Matematika dan IPA. Jember: FKIP Universitas Jember.

Varberg, D., E. J. Purcell \& S. E. Rigdon. (2011). Kalkulus edisi 9, Jilid 2, terjemahan dari Calculus Ninth Edition, oleh I Nyoman Susila. Jakarta: Erlangga.

Weisstein, Eric W. "Hyperbola." From MathWorld-A Wolfram Web Resource. http://mathworld.wolfram.com/Hyoerbola.html 